\title{
BMJ
}

\section{Recurrence up to 3.5 years after antibiotic treatment of acute otitis media in very young Dutch children: survey of trial participants}

\author{
Natália Bezáková, medical student,, ${ }^{1}$ Roger A M J Damoiseaux, general practitioner, ${ }^{2}$ Arno W Hoes, professor \\ of clinical epidemiology and general practice, ${ }^{1}$ Anne G M Schilder, otorhinolaryngologist and clinical \\ epidemiologist, ${ }^{3}$ Maroeska M Rovers, clinical epidemiologist ${ }^{1}$
}

Julius Center for Health Sciences and Primary Care, University Medical Center Utrecht,

PO Box 85060, 3508 AB Utrecht, Netherlands

${ }^{2}$ General Practice de Hof van Blom, 8051 JT Hattem, Netherlands

${ }^{3}$ Department of Otorhinolaryngology, Wilhelmina Children's Hospital, University Medical Center Utrecht

Correspondence to: M M Rovers m.rovers@umcutrecht.nl

Cite this as: $B M J$ 2009;339:b2525 doi:10.1136/bmi.b2525

\section{ABSTRACT}

Objective To determine the long term effects of antibiotic treatment for acute otitis media in young children.

Design Prospective three year follow-up study within the framework of a primary care based, double blind, randomised, placebo controlled trial.

Setting 53 general practices in the Netherlands.

Participants 168 children aged 6 months to 2 years with acute otitis media.

Interventions Amoxicillin $40 \mathrm{mg} / \mathrm{kg} /$ day in three doses compared with placebo.

Main outcome measures Recurrence of acute otitis media; referral to secondary care; ear, nose, and throat surgery.

Results Acute otitis media recurred in $63 \%$ (47/75) of children in the amoxicillin group and in $43 \%$ (37/86) of the placebo group (risk difference $20 \%, 95 \%$ confidence interval $5 \%$ to $35 \%$ ); $30 \%$ (24/78 amoxicillin; $27 / 89$ placebo) of children in both groups were referred to secondary care, and $21 \%(16 / 78)$ of the amoxicillin group compared with $30 \%$ (27/90) of the placebo group had ear, nose, and throat surgery (risk difference $-9 \%,-23 \%$ to $4 \%$ ).

Conclusion Recurrent acute otitis media occurred more often in the children originally treated with amoxicillin. This is another argument for judicious use of antibiotics in children with acute otitis media.

Trial registration Netherlands Trial Register NTR1426.

\section{INTRODUCTION}

Acute otitis media, one of the most common infections in childhood, remains the leading cause of doctors' consultations by children and the most common reason for children to take antibiotics. ${ }^{1}$ Current guidelines recommend prescription of antibiotics in children with severe illness and in those younger than 2 years of age with bilateral acute otitis media or acute otorrhoea. For most other children with acute otitis media, initial observation is recommended. ${ }^{2-4}$

So far, little is known about the long term effects of antibiotics in acute otitis media. Initial prescription of antibiotics may on the one hand shorten the course of acute otitis media. ${ }^{56}$ On the other hand, it may encourage doctors' attendance in future episodes, increase pressure on doctors to prescribe, increase future use of antibiotics, and therefore increase antibiotic resistance. ${ }^{78}$ In addition, antibiotic treatment may cause an unfavourable shift towards colonisation with resistant pathogens, which are likely to promote recurrence of the infection. ${ }^{9-12}$ We aimed to study the long term effects of antibiotics on recurrence of acute otitis media; referrals to secondary care; and ear, nose, and throat surgery.

\section{METHODS}

We did the study within the framework of a primary care based, randomised, placebo controlled, double blind trial on the effects of amoxicillin compared with placebo in children with acute otitis media aged between 6 and 24 months. ${ }^{5}$ The diagnosis of acute otitis media was based on the presence of acute signs of infection and otoscopy. The original study took place in the Netherlands between February 1996 and May 1998 and included 240 children, who were followed actively for six months. ${ }^{513}$ At trial entry, parents were informed that treatment allocation would be revealed only after the final follow-up, including the post-trial period of about three years. Only in case of severe complications or side effects would the treatment code be broken during the trial. The results at days four and 11 and at six months were reported in 2000 and $2006 . .^{513}$

In 2000 - that is, approximately three and half years after the start of the trial-we sent a questionnaire to parents of the participating children, asking them about episodes of recurrent acute otitis media; referral to secondary care; and ear, nose, and throat surgery. We defined the primary outcome measure, reported recurrent acute otitis media, as at least one episode of acute otitis media that occurred between the last study appointment at six months and the current survey. In addition, we compared the proportion of children referred to secondary care (paediatrician or ear, nose, and throat surgeon) and the rate of ear, nose, and throat surgery. 
Table 1|Baseline characteristics. Values are numbers (percentages) unless stated otherwise

\begin{tabular}{|c|c|c|c|c|}
\hline \multirow[b]{2}{*}{ Characteristic } & \multicolumn{2}{|c|}{ Trial $(n=240)$} & \multicolumn{2}{|c|}{ Long term survey $(n=168)$} \\
\hline & Amoxicillin ( $n=117$ ) & Placebo $(n=123)$ & Amoxicillin (n=78) & Placebo $(n=90)$ \\
\hline Mean age at inclusion (months) & 13.3 & 13.4 & 13.5 & 13.1 \\
\hline Male & $64(55)$ & $66(54)$ & $43(55)$ & $45(50)$ \\
\hline Breast fed for $\geq 6$ months & $21(18)$ & $22(18)$ & $17(22)$ & $17(19)$ \\
\hline 12 children in family & $30(26)$ & $25(20)$ & $19(24)$ & $18(20)$ \\
\hline Season of inclusion (Oct-March) & $76(65)$ & $79(64)$ & $52(67)$ & $60(67)$ \\
\hline Smoking in household & $46(39)$ & $39(32)$ & $27(35)$ & $24(27)$ \\
\hline Attendance at day care centre & $28(24)$ & 19 (15) & $19(24)$ & $16(18)$ \\
\hline \multicolumn{5}{|l|}{ Medical history: } \\
\hline Recurrent URTI & $37(32)$ & $33(27)$ & $24(31)$ & $19(21)$ \\
\hline Recurrent AOM in family & $26(22)$ & $33(27)$ & $15(19)$ & $25(28)$ \\
\hline Allergy & $14(12)$ & $9(7)$ & $7(9)$ & $7(8)$ \\
\hline Recurrent AOM & $33(28)$ & $50(41)$ & $21(27)$ & $33(37)$ \\
\hline \multicolumn{5}{|l|}{ Clinical presentation: } \\
\hline 13 days' complaints & $57(49)$ & $54(44)$ & $39(50)$ & $39(43)$ \\
\hline Earache & $82(70)$ & $82(67)$ & $57(73)$ & $58(64)$ \\
\hline Fever & $79(68)$ & $80(65)$ & $51(65)$ & $54(60)$ \\
\hline Perforation & $18(15)$ & $21(17)$ & $13(17)$ & $19(21)$ \\
\hline Bilateral AOM & $75(64)$ & $76(62)$ & $51(65)$ & $55(61)$ \\
\hline Bulging ear drum & $26(22)$ & $29(24)$ & $21(27)$ & $18(20)$ \\
\hline Mean follow-up (months) & NA & NA & 46 & 45 \\
\hline $\begin{array}{l}\text { Subsequent antibiotic use within } \\
6 \text { months* }\end{array}$ & 39/105 (37) & 44/104 (42) & $23 / 73(32)$ & $32 / 81(40)$ \\
\hline
\end{tabular}

In the first instance, we looked only at risk difference and did not adjust for potential confounders, as we were reporting on the long term effects of a randomised placebo controlled trial. To be sure that confounding was not a problem in the post-randomisation period, we also studied the following potential confounders by using logistic regression analysis: mean age at inclusion, sex, breast feeding, number of siblings, season of inclusion, attendance at day care centre, family history of recurrent upper respiratory tract infections, (duration of) symptoms at presentation, subsequent use of antibiotics within six months, and the clinical outcome at days four and 11 and six months.

Finally, we did a sensitivity analysis on the primary outcome restricted to the children in each group who did not receive antibiotics within the first six months of the post-trial follow-up period. We did all analyses with SPSS 14.0 on an intention to treat basis.

\section{RESULTS}

Of the 240 participants originally randomised, 168 $(70 \%)$ returned the questionnaire. At this stage, about

Table 2 |Clinical outcomes between six months and three years after randomised controlled trial. Values are numbers (percentages) unless stated otherwise

\begin{tabular}{lcccc} 
Outcome & $\begin{array}{c}\text { Amoxicillin } \\
(\mathrm{n}=\mathbf{7 8})\end{array}$ & $\begin{array}{c}\text { Placebo } \\
(\mathrm{n}=90)\end{array}$ & $\begin{array}{c}\text { Risk difference } \\
(95 \% \mathrm{Cl})\end{array}$ & $\begin{array}{c}\text { Relative risk } \\
(95 \% \mathrm{Cl})\end{array}$ \\
Recurrent acute otitis media & $47 / 75(63)$ & $37 / 86(43)$ & $20 \%(5 \%$ to $35 \%)$ & $1.5(1.1$ to 2.0$)$ \\
\hline Referral rate & $24(31)$ & $27 / 89(30)$ & $0 \%(-14 \%$ to $14 \%)$ & $1.0(0.6$ to 1.6$)$ \\
\hline Surgery rate & $16(21)$ & $27(30)$ & $-9 \%(-23 \%$ to $4 \%)$ & $0.7(0.4$ to 1.2$)$ \\
\hline
\end{tabular}

$95 \%$ of these parents were still blinded to the original treatment. The baseline characteristics of these 168 children were similar to those initially randomised (table 1).

Three years after randomisation, acute otitis media had recurred in $47 / 75(63 \%)$ children in the amoxicillin group compared with $37 / 86$ (43\%) children in the placebo group (risk difference 20\%, 95\% confidence interval $5 \%$ to $35 \%$ ) (table 2). Logistic regression analysis showed that sex, allergy, and history of recurrent acute otitis media might be relevant confounding factors. Adjustment for these factors resulted in an adjusted odds ratio of 2.5 (95\% confidence interval 1.2 to 5.0 ) - that is, children who were assigned to the amoxicillin group had a 2.5 times higher risk of recurrent acute otitis media than children in the placebo group.

Twenty four out of $78(31 \%)$ children in the amoxicillin group and $27 / 89(30 \%)$ in the placebo were referred to secondary care (risk difference $0 \%,-14 \%$ to $14 \%$ ) (table 2). Finally, 16/78 (21\%) children in the amoxicillin group compared with 27/90 (30\%) children in the placebo group had ear, nose, and throat surgery (risk difference $-9 \%,-23 \%$ to $4 \%$ ).

Sensitivity analysis for the primary outcome measure, comparing only those children in each group who did not receive antibiotics in the first six months of the post-trial follow-up period, showed a risk difference of $32 \%$ (13\% to $51 \%)$ and an adjusted odds ratio of 4.4 (1.7 to 11.5$)$. 


\section{WHAT IS ALREADY KNOWN ON THIS TOPIC}

Antibiotics shorten the course of acute otitis media but encourage doctors' attendance in future episodes and antibiotic resistance

Evidence on the long term effects of antibiotics in children with acute otitis media is lacking

\section{WHAT THIS STUDY ADDS}

Recurrent acute otitis media occurred more often in the children originally treated with amoxicillin

This is another argument for judicious use of antibiotics in children with acute otitis media

\section{DISCUSSION}

Using a questionnaire about recurrent episodes of acute otitis media, we found a $20 \%$ higher recurrence rate in the amoxicillin group compared with the placebo group in the post-trial period between six months and three years after randomisation. The corresponding confidence intervals, however, are wide, so this rate must be interpreted with some caution.

To our knowledge, we are the first group to study the long term effects of antibiotics in children with acute otitis media. Others have studied the effects up to one year and found no differences between the groups. ${ }^{814}$ This seems to be in agreement with our results for the first six months of follow-up, in which we found similar recurrence rates in the amoxicillin and placebo group ( $51 \%$ v 50\%; risk difference 1\%, 95\% confidence interval $-12 \%$ to $15 \%$ ).

Our findings might be explained by unfavourable changes in the colonisation of the nasopharynx as a result of the use of antibiotics, as reported previously. ${ }^{9-12}$ Alternatively, the use of antibiotics early in an episode of acute otitis media may impair the natural immune response and weaken the protection against further episodes, as has been suggested in studies of bacterial pharyngitis. ${ }^{15-17}$ Importantly, both possible explanations would primarily have resulted in a difference in recurrence of acute otitis media in the first six months of follow-up, which was not the case. Nevertheless, our findings are very robust: unadjusted, adjusted, and sensitivity analyses showed a relevant clinical difference.

The major strength of our study is the fact that most parents were still blinded to the original treatment when they filled in the questionnaire. Furthermore, by using a questionnaire we measured true recurrences rather than reattendances.

Some possible limitations deserve further discussion. Firstly, under-reporting or over-reporting of acute otitis media cannot fully be precluded, as the outcomes were based on parental reports. The recurrence rates might therefore be biased, but we would expect a similar effect in both groups, especially as most parents were still blinded when they participated in the current survey. Thus recall bias is unlikely.

Secondly, $70 \%$ of the parents who participated in the randomised controlled trial returned the questionnaire. This might potentially have led to selection of otitis prone children. The baseline characteristics of the children whose parents responded were, however, similar to those of the original trial population.

Thirdly, we did not do a Cox regression analysis, as we measured only the number of recurrent episodes after three years. As the mean follow-up times were similar in both groups, however, we do not expect that Cox regression would have changed our results.

Fourthly, our results can be generalised only to otherwise healthy children in well resourced settings. Acute otitis media can become a serious illness in children at risk and in those in less resourced settings, and this may call for a more active approach to treatment.

Fifthly, owing to the delay in reporting the results of this survey, changes in practice since then may have reduced the applicability of our results. As antibiotics are still widely prescribed in young children with acute otitis media, ${ }^{18}$ however, we believe that the results of our study are still applicable to current day to day practice.

In conclusion, recurrent acute otitis media occurred more often in the children originally treated with amoxicillin. This is another argument for judicious use of antibiotics in children with acute otitis media.

We thank the participating children and all the general practitioners who included patients in this trial.

Contributors: NB analysed and interpreted the data. RAMJD was responsible for the design, planning, and data collection of the original trial and contributed to the initial concept and data interpretation of the study. MMR supervised the study and interpreted the data. AWH and AGMS contributed to the data interpretation. NB and MMR prepared the manuscript, and all authors commented on it. MMR is the guarantor. Funding: Netherlands Organisation for Scientific Research (grant No 90458074) funded the original trial.

Competing interest: MMR has participated in a CME accredited symposium on the burden of otitis media, which was supported by an unrestricted grant from GlaxoSmithKline.

Ethical approval: The ethics committee of the University Medical Center Utrecht approved the protocol.

1 Rovers MM, Schilder AGM, Zielhuis GA, Rosenfeld RM. Otitis media. Lancet 2004;363:465-73.

2 American Academy of Pediatrics Subcommittee on Management of Acute Otitis Media. Diagnosis and management of acute otitis media. Pediatrics 2004;113:1451-65.

3 Damoiseaux RAMJ, Van Balen FAM, Leenheer WAM, Kolnaar BGM. NHG-standaard otitis media acuta bij kinderen. [Guideline on acute otitis media of the Dutch College of General Practitioners.] Huisarts Wet 2006;49:615-21.

4 Rovers MM, Glasziou P, Appelman CL, Burke P, McCormick DP, Damoiseaux RA, et al. Antibiotics for acute otitis media: a metaanalysis with individual patient data. Lancet 2006;368:1429-35.

5 Damoiseaux RAMJ, van Balen FAM, Hoes AW, Verheij TJM, de Melker RA. Primary care based randomised, double blind trial of amoxicillin versus placebo for acute otitis media in children aged under 2 years. BMJ 2000;320:350-4

6 Glasziou PP, Del Mar CB, Sanders SL, Hayem M. Antibiotics for acute otitis media in children. Cochrane Database Syst Rev 2004;(1):CD000219.

7 Williamson I, Benge S, Mullee M, Little P. Consultations for middle ear disease, antibiotic prescribing and risk factors for reattendance: a case-linked cohort study. Br / Gen Pract 2006;56:170-5.

8 Little P, Moore M, Warner G, Dunleavy J, Williamson I. Longer term outcomes from a randomised trial of prescribing strategies in otitis media. Br J Gen Pract 2006;56:176-82.

9 Ghaffar F, Muniz LS, Katz K, Smith JL, Shouse T, Davis P, et al. Effects of large dosages of amoxicillin/clavulanate or azithromycin on nasopharyngeal carriage of Streptococcus pneumoniae, Haemophilus influenzae, nonpneumococcal a-hemolytic streptococci, and Staphylococcus aureus in children with acute otitis media. Clin Infect Dis 2002;34:1301-9.

10 Dagan R, Leibovitz E, Cheletz G, Leiberman A, Porat N. Antibiotic treatment in acute otitis media promotes superinfection with 
resistant streptococcus pneumoniae carried before initiation of treatment. J Infect Dis 2001;183:880-6.

11 Brook I, Gober AE. Antimicrobial resistance in the nasopharyngeal flora of children with acute otitis media and otitis media recurring after amoxicillin therapy. J Med Microbiol 2005;54:83-5.

12 Heikkinen T, Saeed KA, McCormick DP, Baldwin C, Reisner BS, Chonmaitree T. A single intramuscular dose of ceftriaxone changes nasopharyngeal bacterial flora in children with acute otitis media. Acta Paediatr 2000;89:1316-21.

13 Damoiseaux RAMJ, Rovers MM, van Balen FAM, Hoes AW, de Melker RA. Long-term prognosis of acute otitis media in infancy: determinants of recurrent acute otitis media and persistent middle ear effusion. Fam Pract 2006;23:40-5.

14 Burke P, Bain J, Robinson D, Dunleavey J. Acute red ear in children: controlled trial of non-antibiotic treatment in general practice. $B M J$ 1991;303:558-62.
15 Pichichero ME, Casey JR. Systematic review of factors contributing to penicillin treatment failure in Streptococcus pyogenes pharyngitis. Otolaryngol Head Neck Surg 2007;137:851-7.

16 Zwart S, Sachs AP, Ruijs GJ, Gubbels JW, Hoes AW, de Melker RA. Penicillin for acute sore throat: randomised double blind trial of seven days versus three days treatment or placebo in adults. $B M$ J 2000;320:150-4.

17 Little P, Williamson I, Warner G, Gould C, Gantley M, Kinmonth AL. Open randomised trial of prescribing strategies in managing sore throat. BMJ 1997;314:722-7.

18 Thompson PL, Gilbert RE, Long PF, Saxena S, Sharland M, Wong IC. Has UK guidance affected general practitioner antibiotic prescribing for otitis media in children? J Public Health 2008;30:479-86.

Accepted: 17 February 2009 